To exhibit it a glance the differences in the males the following table is added : Anterior ventral segments pubescent at middle, front thighs toothed.

Front tibiæ angulate.

Hind thighs not toothed, prosternum velvety pubescent at middle.

A. sculptile.

Hind thighs toothed, prosternum smooth.

Front tibiæ sinuate, not at all angulate, prosternum smooth, hind tibiæ with stronger apical process.

C.

Ventral surface without velvety pubescence along the middle, front thighs not toothed, front tibiæ not angulate, apical processes of middle and hind tibiæ very long.

D. calcaratum.

C. sculptile Newm. is not rare in the
Atlantic States. Colcaratum Lec is from Or. and V.I.

Were the above described secondary $\delta$ characters in $\mathrm{A}, \mathrm{B}$, and $\mathrm{C}$, accompanied by any constant differences in form or sculpture, three very distinct species would seem to be indicated; but there does not appear to be the slightest clew to show which females belong with any of the males, and it is perhaps not impossible that a series of specimens may prove that the $q$ of $D$, is not easily distinguishable from the eastern forms.

In conclusion it is suggested that those who are located within the faunal limits of Clinidium examine their material for the purpose of learning if all the variations mentioned, or any others not yet noted, occur in one locality. In the vicinity of Lowell the family does not appear to be represented.

\title{
SOME NEW COMPARISONS OF PIERIS OLERACEA WITH P. NAPI.
}

BY SAMUEL HUBBARD SCUDDER, CAMBRIDGE, MASS.

As Pieris oleracea of North America has been regarded as identical with $P$. napi of Europe by some who have studied only the markings of the wings, I have thought a comparison based on the early stages would be desirable; this I am now able to make by the kindness of Mr. J. Jenner Weir of England, who has kindly sent me a number of specimens of blown larvae and living chrysalids of the latter. Other caterpillars from the continent have been ofservice.

The mature caterpillar of $P$. oleracea differs from that of $P$. napi of Europe in the more uniform pile with which the body is clothed, and by the apparent absence of those comparatively large conical wartlets, ten or twelve times larger than the smaller ones, which form so conspicuous a feature in both $P$. napi 
and $P$. rapae, and which are arranged at subequidistant intervals in a transverse row on each of the subsegments of the body; they are present in $P$. oleracea, but are not nearly so large relatively as in $P$. napi, except possibly on the stigmatal subsections of the anterior part of the body, and are further inconspicuous in being either concolorous with the body, or white, or only a little infuscated, while in both the other species mentioned they are piceous and most conspicuous; occasionally, however, when white, they are marked with a fuscous annulus around the base and so are made more conspicuous, but herein they approach the normal type of P. rapae and not of P. napi.

The chrysalis of $P$. oleracea differs from that of P. napi of Europe, first, in the following structural features: the frontal tubercle curves distinctly upward, while that of $P . n a p i$ is directed straight forward ; the elevation of the suprastigmatal carina to a distinct, spinous, compressed tubercle on the sides of the anterior part of the third abdominal segment, is far more marked, and the tubercle itself distinctly flares laterally, which that of $P$. napi cannot be said to do. Second, in colorational peculiarities: Chrysalids of $P$. napi are far more heavily marked; especially the suprastigmatal carina is margined interiorly with large blackish uscous patches forming a more or less interrupted band over the second to the eighth abdominal segments; the fourth of the tenth segments have a distinct mediodorsal black dash at the anterior margin ; and the disk of the wing cases is marked with a double black dash besides the black specks; none of these markings are present in $P$. oleracea except the first named, on the second and third segments, and occasionally a fuscous indication posterior to that ; the black specks or dots are found on the wing cases, but the black dashes are wanting. The further dorsal markings of the abdomen of $P$. napi consist, on most of the segments, of a curving or diverging series of black dots, three on a side next the middle line above, open posteriorly, and an oblique arrangement of two black dots on either side, nearer the suprastigmatal than the mediodorsal carina, the anterior marginal or submarginal and the outer, the other anterocentral and the inner; none of these except the submarginal dot of the outer series is found at all in P. oleracea, and then only, as a general rule, on the third to the sixth segments and accompanied on the fifth and sixth by a companion dot, sometimes double, a little way above the spiracle.

The male imago of $P$. oleracea differs structurally from that of $P$. napi in the hook of the upper organ of the abdominal appendages, which is shorter and more strongly curved at tip, while the semicorneous expansion of the under edges of the base is not a downward directed, vertical lamina, thickening into a posterior, downward directed thorn, but a short curved hook, opposed to the hook of the upper organ. 

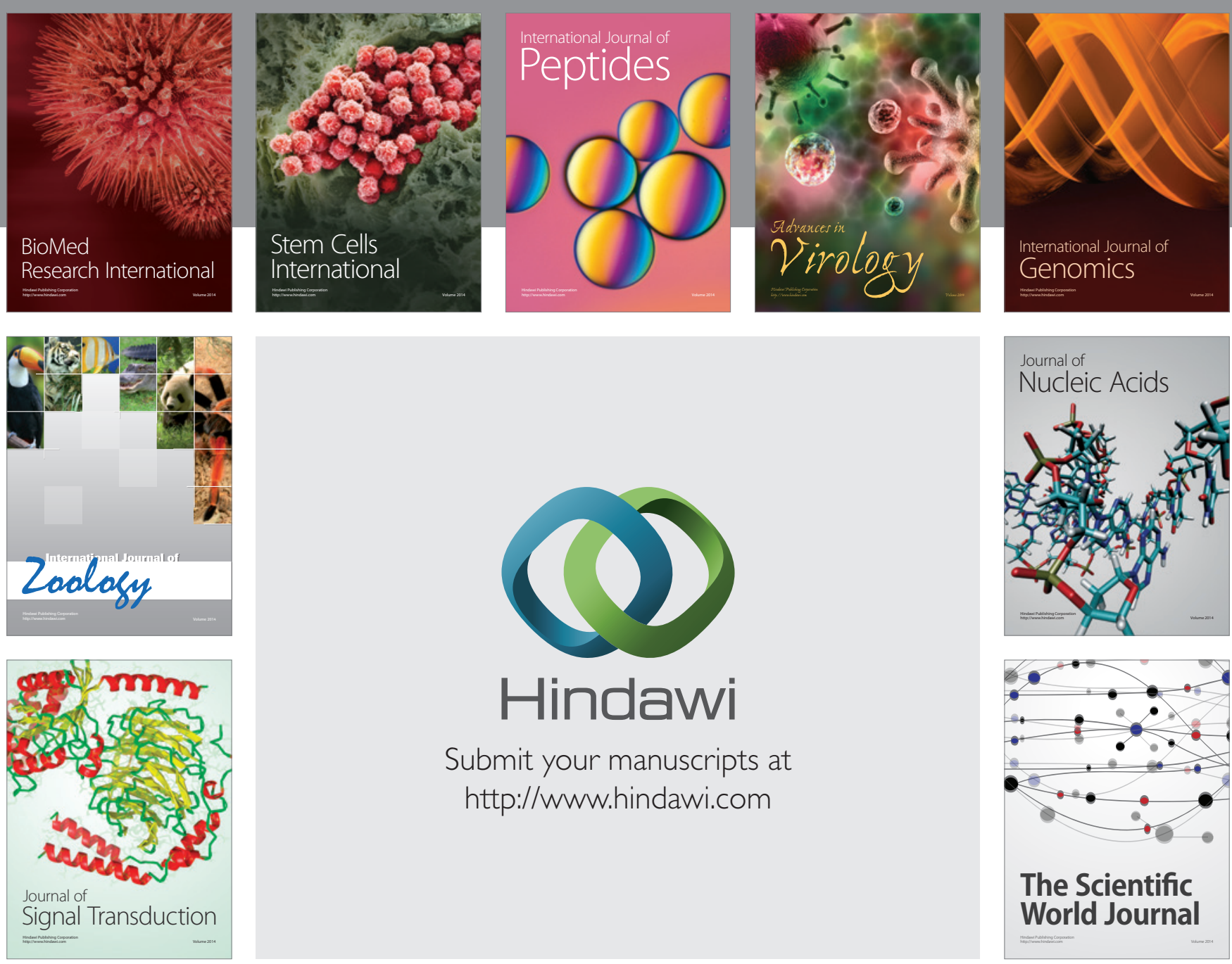

Submit your manuscripts at

http://www.hindawi.com
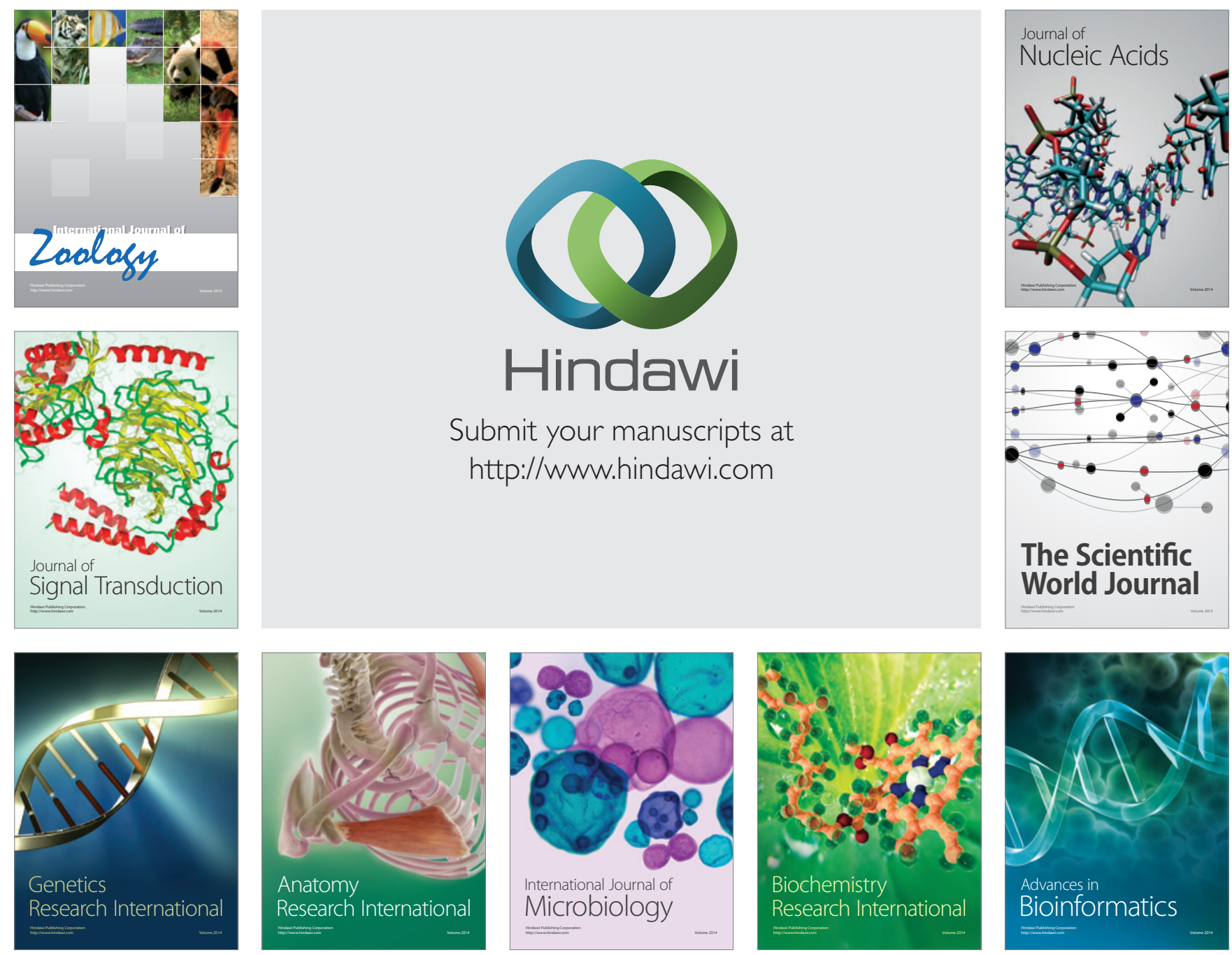

The Scientific World Journal
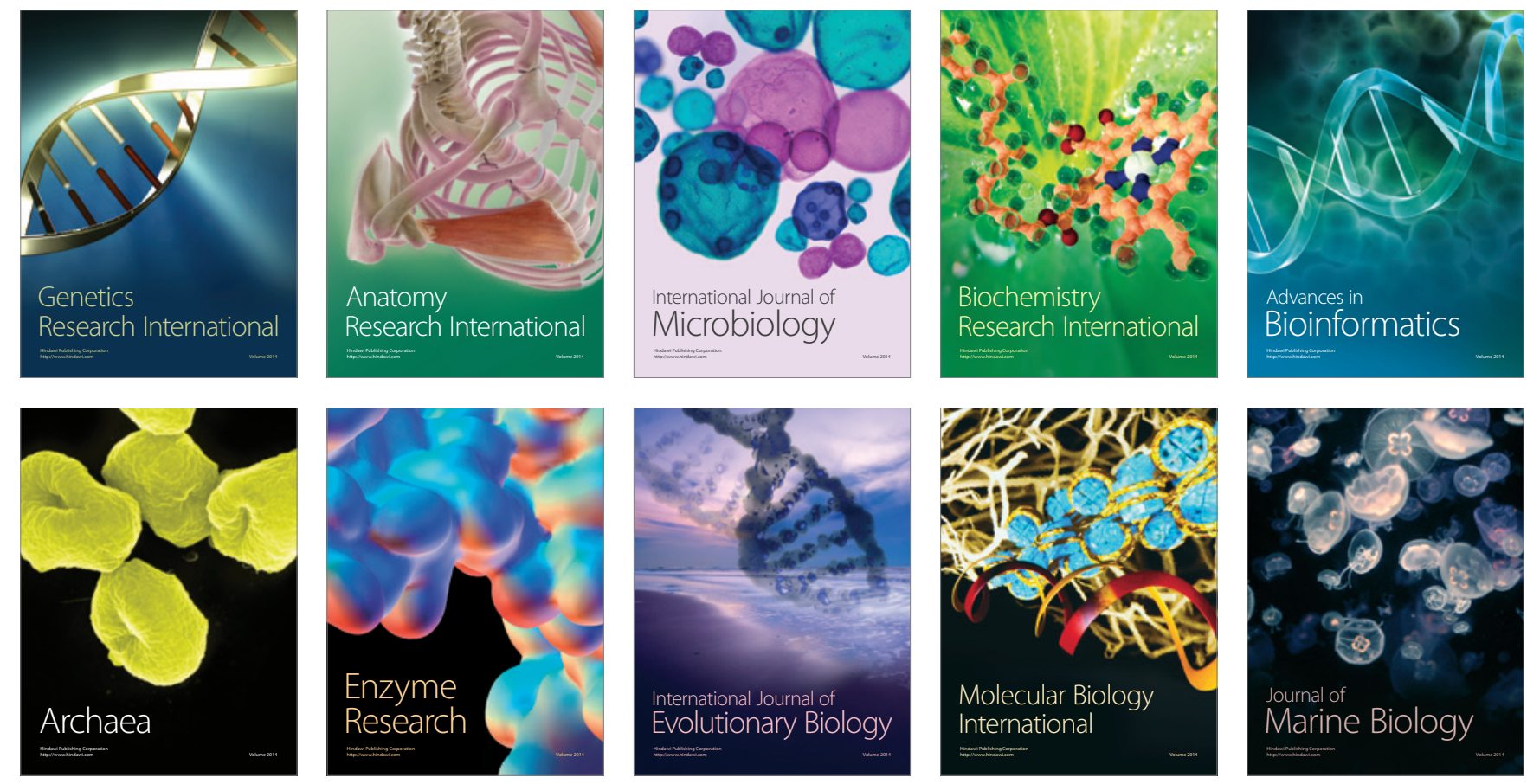